Artículo Original

\section{Efectividad antimicrobiana} in vitro del Papacarie ${ }^{\circledR}$ en muestras de tejido cariado en escolares de educación primaria

Antimicrobial effectiveness in vitro of the Papacarie ${ }^{\oplus}$ in samples from the decayed tissue in primary school students

\section{Resumen}

Con la finalidad de comprobar la actividad antimicrobiana del Papacarie ${ }^{\oplus}$ en el tiempo indicado por el fabricante (30 s), se tomaron muestras de tejido cariado de piezas deciduas sin compromiso pulpar de cinco nińos de la Institución Educativa Andrés Rázuri, para analizar in vitro la muestra con el producto. Tomando en cuenta que el producto requiere estar en contacto con la muestra un corto tiempo, se embebieron discos con el Papacarie ${ }^{\oplus}$ y se enfrentó a esta por 15, 30 y 60 segundos; luego, se retiraron los discos y se sembró la muestra en Agar Mitis Salivarius Bacitracina. Los conteos obtenidos de los controles realizados a las 24, 48 y 72 horas, fueron analizados con la prueba estadística Prueba T de Student. Los resultados obtenidos demuestran que con la metodología empleada no existen diferencias significativas entre la actividad antimicrobiana y los tiempos de aplicación del Papacarie ${ }^{\circ}$.

Palabras clave: Papacarie ${ }^{\oplus}$, actividad antimicrobiana, caries dental.

\section{Abstract}

With the purpose of determinate the antimicrobial activity of the Papacarie ${ }^{\varpi}$ in the time indicated by the manufacturer (30seconds), samples were taken from caused to decay weave of temporary pieces without commitment to pulpar of five children of the school Andrés Rázuri, to analyze in vitro the sample with the product. Taking into account that the product requires to be in contact with the sample a short time, discs with the Papacarie ${ }^{\oplus}$ became absorbed and faced this by 15,30 and 60 seconds, the discs were retired and the sample in Agar Mitis Salivarius Bacitracina was seeded. The obtained counts of the controls made to 24, 48 and 72 hours, were analyzed with T Student statistical analysis. The results demonstrated that with the used methodology a significant difference between the antimicrobial activity and the indicated application times does not exist.

Key words: Papacarie ${ }^{\oplus}$, antimicrobial activity, dental decay.

\section{Verónica Alvarado Villanueva1 Lito Azaña Espinoza ${ }^{1}$ Dany Cosco Robles ${ }^{1}$ Pedro Díaz Montes ${ }^{1}$ Sandra Fernández Vivas ${ }^{1}$ Jeinmy Li Albrizzio ${ }^{1}$ Katia Medina Calderón ${ }^{2}$ Hilda Moromi Nakata ${ }^{3}$ Margot Gutiérrez llave ${ }^{4}$ Lita Ortiz Fernández²}

\footnotetext{
Estudiantes de la Facultad de Odontología de la Universidad Nacional Mayor de San Marcos

2 Profesora Auxiliar del D.A. de Estomatología Preventiva y Social UNMSM

3 Profesora Principal del D.A. de C. Básicas UNMSM

${ }^{4}$ Profesora Principal del D.A. de Estomatología Preventiva y Social UNMSM
}

Correspondencia:

CD. Katia Medina Calderón Facultad de Odontología UNMSM Germán Amézaga s/n, Lima - Perú

Correo electrónico: medina.katia@gmail.com

\section{Introducción}

Las enfermedades bucodentales, como la caries dental, la enfermedad periodontal, los cánceres de la boca y la faringe, son un problema de salud de alcance mundial que afecta a los países industrializados y, cada vez con mayor frecuencia, a los países en desarrollo, en especial entre las comunidades más pobres; un informe de la Organización Mundial de la Salud (OMS) ha declarado que se estima que cinco mil millones de personas en el planeta han sufrido caries dental ${ }^{1}$. Si bien la bacteria S. mutans es la principal responsable de la caries, se han encontrado otros factores que también muestran una inesperada correlación con este problema ${ }^{2}$ : complicaciones durante el embarazo o el parto, nacimiento prematuro o por cesárea, diabetes materna, enfermedades renales, incompatibilidades del Rh, alergias, gastroenteritis frecuentes y diarrea crónica. Se realizan acciones de promoción de salud y prevención de enfermedades con el objetivo de disminuir su incidencia, entre las que se destacan las dirigidas a la educación de la población para mejorar sus hábitos higiénicos, nutricionales y aquellas encaminadas a incrementar la resistencia del diente con la utilización de fluoruros, ya sea por vía tópica o sistémica. ${ }^{1}$ El tratamiento de última generación químico-mecánica de la caries dental es presentado por la OMS como alternativa al tratamiento restaurador convencional. ${ }^{3-5,10}$ Está indicado para actuar en zonas donde no presenta una tecnología adecuada (luz eléctrica, agua, agüe), zonas donde más se presenta la enfermedad. ${ }^{4}$
En vista de ello, el objetivo de este estudio fue determinar la efectividad antimicrobiana in vitro del Papacarie ${ }^{\varpi}$ en relación al tiempo de exposición, en muestras de tejido cariado en escolares de educación primaria en el 2006.

\section{Material y Método}

\section{Tipo de estudio}

De tipo experimental, in vitro, longitudinal con controles a las 24, 48 y 72 horas.

\section{Población de estudio}

La población estuvo conformada por escolares de primaria de la I.E. "Andrés Rázuri” del distrito de San Martín de 
Porres, ámbito de la clínica periférica "Playa Rímac".

\section{Muestra}

Se seleccionaron cinco escolares que fueron elegidos de acuerdo a los siguientes criterios de inclusión.

- Presencia de, al menos, un diente deciduo cariado sin compromiso pulpar.

- Los dientes deciduos no presentaron ningún tipo de sintomatología previa o actual.

- Los dientes deciduos no presentaron lesión a nivel de tejidos blandos.

- Los dientes deciduos no presentaron restauraciones con caries recidivantes.

\section{Recolección de datos}

\section{Procedimiento clínico}

- Se extrajo el tejido cariado de los dientes de cada niño utilizando una cureta con filo y las muestras se colocaron en un recipiente estéril con suero fisiológico.

- Se realizó el tratamiento restaurador provisional con cemento de óxido de zinc y eugenol.

\section{Fase microbiológica?}

- En el laboratorio, la muestra se homogenizó en un vórtex.

- Se sembró en placas petri con Agar Mitis salivarius Bacitracina para obtener el desarrollo de las colonias de Streptococos del grupo mutans.

- A las 24 horas, se tomaron colonias desarrolladas en esta placa y se diluyeron en $100 \mathrm{ml}$ de suero fisiológico.

- Se tomó $1 \mathrm{ml}$ de la dilución y se enfrentó a 5 mg de Papacarie ${ }^{\oplus}$, se homogenizó en el vórtex y se sembró con un asa de siembra en placa petri con AMSB. Se repitió este paso cinco veces.

- El mismo procedimiento se realizó a los 15, 30 y 60 segundos.

- Se realizó el conteo de unidades formadores de colonias (UFC) a los 24,48 y 72 horas.

Se utilizó una ficha de recolección de datos para evaluar los cambios microbiológicos in vitro, donde se anotaron
Tabla 1. Recuento promedio UFC según el tiempo de exposición con Papacarie ${ }^{\circledast}$ tiempo de control.

\begin{tabular}{|c|c|c|c|c|c|c|}
\hline \multirow{3}{*}{$\begin{array}{l}\text { Tiempo de } \\
\text { exposición en } \\
\text { segundos }\end{array}$} & \multicolumn{6}{|c|}{$\begin{array}{c}\text { Promedio de UFC } \\
\text { Total }\end{array}$} \\
\hline & \multicolumn{2}{|c|}{24 horas } & \multicolumn{2}{|c|}{48 horas } & \multicolumn{2}{|c|}{72 horas } \\
\hline & $\begin{array}{r}\text { Prome } \\
\text { D }\end{array}$ & & Promedio & Des. Est. & Promedi & Des. Est. \\
\hline 15 & 0,0 & 0,000 & 3668 & 200,324 & 4,448 & 57,149 \\
\hline 30 & 0,4 & 0,490 & 3664 & 109,356 & 4,414 & 130,632 \\
\hline 60 & 0,0 & 0,000 & 3212 & 197,727 & 4,140 & 88,652 \\
\hline
\end{tabular}

el número de unidades formadoras de colonias (UFC) observadas en los diferentes tiempos.

\section{Resultados}

En el tabla 1, se observan los resultados obtenidos a los 15, 30 y 60 segundos de exposición al Papacarie ${ }^{\circledast}$, obteniéndose después de 15 segundos un promedio de 0 UFC a las 24 horas; de 3668 a las 48 horas y de 4488 a las 72 horas de control. A los 30 segundos, se obtuvo un promedio de 0,4 a las 24 horas, 3664 a las 48 horas y de 4144 a las 72 horas de control. Y a los 60 segundos, se obtuvo un promedio de 0 a las 24 horas; de 3212 a las 48 horas y de 4140 a las 72 horas de control. Según el análisis estadístico ANOVA, se encontró un valor P de 0,930 , el cual indica que no existen diferencias estadísticamente significativas entre las lecturas realizadas, porque se encontraron resultados similares en 15, 30, y 60 segundos de exposición con Papacarie ${ }^{\circledast}$.

\section{Grupo control y grupo experimental}

En el tabla 2, se muestra que en el grupo de control sin exposición al Papacarie ${ }^{\circledast}$ se obtuvo un promedio 0 UFC a las 24 horas, 4000 UFC a las 48 horas y de 6 000 UFC a las 72 horas. Mientras que el grupo experimental con exposición al Papacarie $^{\oplus}$, se obtuvo un promedio de UFC a las 24 horas de 0,13 , a las 48

horas de 3514,66 y a las 72 horas de 4257,33 . En ambos casos, se utilizaron los promedios obtenidos a los 15, $30 \mathrm{y}$ 60 segundos. Estos resultados se analizaron con la Prueba T de Student para grupos independientes encontrándose que la diferencia no es estadísticamente significativa.

Resulta notorio que el número de UFC fue prácticamente nulo a las 24 horas en todos los tiempos de exposición, y aumentó a las 48 y 72 horas, lo que podría evidenciar el efecto inmediato del Papacarie ${ }^{\circledast}$, pero que se pierde o disminuye conforme avanza el tiempo y las bacterias recuperan su viabilidad, sugiriendo la acción bacteriostática del producto.

\section{Discusión}

En un estudio realizado por Bussadori y col. en el año $2003,{ }^{2}$ demostraron la efectividad antimicrobiana del Papacarie $^{\circledast}$ a los 30 segundos; sin embargo, en nuestro estudio, los resultados de la actividad antimicrobiana no mostraron diferencias significativas en los distintos tiempos de exposición: 15, 30 y 60 segundos.

Pereira y col, ${ }^{4}$ en el año 2004 , comprobaron mayor actividad antimicrobiana del Papacarie ${ }^{\oplus}$ para S. mutans. Igualmente, en el presente estudio, cabe destacar que se observó la actividad antimicrobiana ante Etreptococos del grupo mutans.

Tabla 2. Recuento promedio de UFC entre el grupo control y el grupo experimental.

UFC

\begin{tabular}{lcccc} 
Tiempo de control & \multicolumn{3}{c}{ Grupo Experimental } & \multicolumn{1}{c}{ Grupo Control } \\
\cline { 2 - 5 } & \multicolumn{1}{c}{ Promedio } & Des. Est. & & \\
\cline { 2 - 4 } 24 horas & 0,133 & 0,352 & 0,000 & 200,324 \\
48 horas & 3514,667 & 285,734 & 4000,000 & 109,356 \\
$\mathbf{7 2}$ horas & 4257,333 & 196,404 & 6000,000 & 197,727 \\
\hline
\end{tabular}




\section{Conclusiones}

Los resultados del estudio permiten determinar que en los 15,30 y 60 segundos de exposición al Papacarie ${ }^{\odot}$ y en lecturas a las 24, 48 y 72 horas, no se encontraron diferencias significativas en el número de UFC de Streptococcus del grupo mutans, a pesar que hubo mayor crecimiento a las 48 y 72 horas.

Se evidenció que a las 24 horas, existe una inhibición inicial del crecimiento de estas bacterias; sin embargo, conforme el tiempo avanza, los microorganismos van recuperando su viabilidad.

\section{Referencias bibliográficas}

1. Ammari et al. Remocao químico mecánica da carie, evidencias atuais. Revista Investigación Brasileña de Odontología 2006.

2. Bussadori et al. Avaliacao da Biocompatibilidade in vitro de um novo material para a Remocao Química e Mecánica da Carie - Papacarie. Pesq. Bras Odontoped Clin Integr 2005; 5(3):254-259.
3. Raulino da Silva et al. Utilización del gel de papaya para la remoción de la caries; reporte de un caso con seguimiento clínico de un año en el 2004. Revista Venezolana 2005; 43(2).

4. Pereira et al. Remocao químico mecánica da carie por meio do gel papacarie .RGO 2004; 52(5).

5. Guillén et al. Efectividad reblandecedora de caries y antimicrobiana del CARISOLV como tratamiento restaurador atraumático. Rev Odontología Sanmarquina 2003; 6(12).

6. Corzo ME: Estudio de la Pre - purificación de la papaina a partir del látex de papaya. Tesis Bachiller. Facultad de Industrias Alimentarías UNALM, Lima, Perú. 1995. 87.

7. Cáceres BS. Estudio sobre las "Plantas medicinales e insumos vegetales para la industria química” del Producto Papaina. Tesis para Magister. Facultad de Agricultura - UNALM, Lima, Perú. 1984.
8. Jo Chiok. Estudio sobre la extracción y valuación de enzimas proteolíticas de Papaya en Perú. Tesis Mg. Facultad de Agricultura - UNALM. Lima, Perú 1966.

9. Moromi et al. Manual de prácticas de microbiología general y estomatológica. UNMSM. Lima, Perú. 2002

10. Papacarie ${ }^{\circledast}$ remoción químico, mecánica de carie - fórmula patentada laboratorio farmacéutico Ltda. Disponible en (citado el 05/09/06): www.formulaeacao.com.br

Fecha de recepción: 5-5-10

Fecha de aprobación: 10-06-10 